\title{
Propagation modes of 3D scour below a submarine pipeline in oblique steady currents and waves
}

\author{
Z.P. Zang \\ Institute of Mechanics, Chinese Academy of Sciences, Beijing, China \\ G. Tang \\ State Key Laboratory of Coastal and Offshore Engineering, Dalian University of Technology, Dalian, China
}

L. Cheng

State Key Laboratory of Coastal and Offshore Engineering, Dalian University of Technology, Dalian, China School of Civil, Environmental and Mining Engineering, The University of Western Australia, Crawley, WA, Australia

\begin{abstract}
This paper presents experimental results on 3D scour propagation along a pipeline under oblique-incidence currents and waves. Different modes of 3D scour propagation were discovered after the local scour was initiated below the pipeline. These modes include scour propagation throughout the whole pipeline, onset of scour at multiple locations due to piping, termination of scour propagation induced by backfill and no scour propagation. The critical conditions for these scour propagation modes were determined in terms of flow incident angle, embedment depth and Shields parameter (or KC number).
\end{abstract}

\section{INTRODUCTION}

Most of the existing studies on local scour below pipelines were concerned with the conditions of wave/current perpendicular to the pipeline. Issues of engineering significance regarding two-dimensional scour subject to currents and waves have been extensively studied through experimental and numerical investigations (Chiew, 1990; Sumer and Fredsøe, 1991; Boros, 1999; Sumer et al., 2001; Li and Cheng, 1999; Fuhrman et al., 2014). Since the local scour is generally three-dimensional due to the scour propagation along the axis of the pipeline, hence there are also several studies focused on the three-dimensional scour, especially on the 3D scour propagation rate along the pipeline. (Cheng et al., 2009, 2014; Wu and Chiew, 2012, 2013).

However, in practical applications, the flows may attack the pipeline at various angles. It was indicated that larger incident angle generally lead to stronger axial flow and secondary axial vortices in the cylinder wakes, resulting in the strong three dimensionality for the flow (Zhou et al. 2010). Thus, the local scour below pipelines under an oblique-incidence flow would be more complex than the normal-incidence cases. Till now, the investigations on the effect of the incident flow angle on the scour below pipelines have been limited. Cheng et al. $(2009,2014)$ conducted a series of experiments on the 3D scour below pipelines subjected to steady currents, waves and combined waves and currents. Effects of the flow incident angle, pipeline embedment depth on the scour propagation rate along the pipeline were investigated and general predictive formulae were proposed. It has also been observed from the experiments that the incident flow angle has significant effect on the time scale and the equilibrium depth of scour.

The flow incident angle may also have significant effect on the mode of $3 \mathrm{D}$ scour propagation along the pipeline. In the 3D scour tests by Cheng et al. $(2009,2014)$, once the scour was initiated below the pipeline, different modes occurred on the 3D scour process as follows, 1) scour propagated over the total length of the pipeline; 2) onset of scour due to piping took place simultaneously along the whole pipeline; 3 ) scour only propagated for a certain distance, and then ceased or backfilled; and 4) scour did not propagate any further due to the backfill of the initial scour hole. The different modes of the $3 \mathrm{D}$ scour process may be dependent on the flow parameters, such as the incident flow angle, the embedment depth, and the flow velocity (or wave parameters), etc. Thus, the main objective of this paper is to determine the critical conditions for the different modes of the 3D scour propagation. 
The work reported in this paper can be considered as an extension of the investigations on 3D scour below a pipeline by Cheng et al. $(2009,2014)$. The time-dependent scour depths along the pipeline, measured by conductivity scour probes, were analyzed. Flow conditions include both steady currents and waves. The critical conditions for different modes of $3 \mathrm{D}$ scour propagation along the pipeline were obtained.

\section{METHODOLOGY AND TEST SETUP}

The physical experiments on 3D scour below pipelines were conducted in a current/wave flume of $4 \mathrm{~m}$ in width, $2.5 \mathrm{~m}$ in depth and $50 \mathrm{~m}$ in length at the State Key Laboratory of Coastal and Offshore Engineering, Dalian University of Technology, China. The current/wave flume is equipped with an irregular wave maker which can generate both regular and irregular waves, and a bi-directional current making system. The maximum wave height can be up to about $0.6 \mathrm{~m}$ and wave period ranges from $0.5 \mathrm{~s}$ to $5.0 \mathrm{~s}$. The maximum pump discharge capacity is $1.0 \mathrm{~m}^{3} / \mathrm{s}$.

A concrete sand pit of $4 \mathrm{~m}$ long, $4 \mathrm{~m}$ wide and $0.25 \mathrm{~m}$ deep was built in the test section. The transitions from the original flume bed to test section and from test section back to the original flume bed are achieved through two 1:20 slopes on both ends of the sand pit. The upstream end of the sandpit is $13.5 \mathrm{~m}$ from the flow inlet, and the downstream end is $6.5 \mathrm{~m}$ from the flow outlet. The water depth in the test section was maintained at $0.45 \mathrm{~m}$ for all the tests to obtain the desired flow velocity range. The schematic experimental setup is shown in Figure 1.

A clear Perspex model pipeline of diameter $D=50 \mathrm{~mm}$ with $8 \mathrm{~mm}$ wall thickness was used in the tests. The surface of the pipeline is smooth. The original model pipeline is comprised of two $2 \mathrm{~m}$ separate sections. Thus the total length of the model pipe is the same as the width of the water flume. A total of 30 pairs stainless steel conductivity probes with $80 \mathrm{~mm}$ long were installed at an interval of $120 \mathrm{~mm}$ along the pipeline to monitor the real time development of scour, as shown in Figure 2. For the tests with current/waves were oblique to the model pipe, the original model pipe

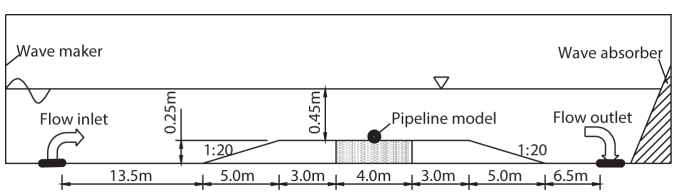

Figure 1. Experimental setup. was extended to the flume walls by connecting two equal length dummy model pipes at both the ends of the model pipe. No scour probes were installed on the dummy pipe sections. In order to increase the rigidity of the model pipeline and fix the scour probes on the model pipeline, the model pipeline was filled with epoxy resin after the installation of probes. The model pipeline was supported in the middle section and at both ends of the pipeline via adjustable screws and nuts fixed to the floor so as to prevent potential movement or sagging of the model pipeline during the tests.

The three-dimensional scour tests were conducted in the sand pit. The model pipeline was partially embedded in the sand across the width of the flume at a pre-determined incident angle to the incoming flow. A simple levelling device, previously used in Cheng et al. (2009), was used to ensure consistent embedment depth along the full length of the model pipeline. At the beginning of each test, a small hole (also called worm hole) was dug underneath the model pipe at the middle section of the pipeline to allow scour propagation in both directions towards the flume walls. Tests were carried out at a range of embedment depths, flow velocities and incident angles in order to investigate their effects on 3D scour propagation.

Extensive tests have been carried out to calibrate the accuracy and stability of the probes. It was found that the accuracy of the probes used in the present test is $+/-0.5 \mathrm{~mm}$ for a wide range of sediment types. An Acoustic Doppler Velocimeter (ADV) was placed at a $2.0 \mathrm{~m}$ upstream location of the pipeline to measure the average flow velocities at $25 \mathrm{~mm}$ (about $50 \%$ of model pipe diameter) above the bed, while a wave probe was placed at $2.0 \mathrm{~m}$ upstream of the model pipe. As the sizes of ADV and wave probe are relatively small to the flume size and are also far enough from the model pipe, the effects of ADV and wave probe on the incoming flows can be neglected. The vertical profile of the mean horizontal velocity component has been obtained before the formal tests, and the results showed good satisfaction to the logarithmic law. The details of the incoming velocity profile can be found in Cheng et al. (2009).

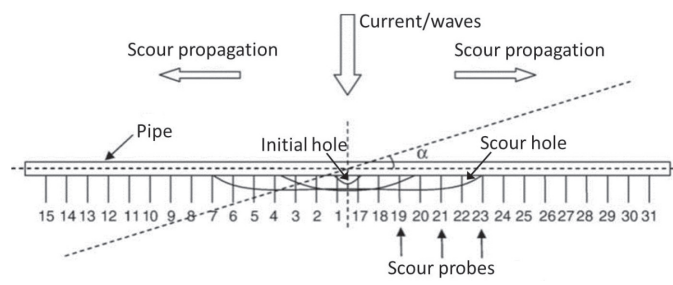

Figure 2. Sketch of model pipeline with scour probes. 
In this study, a total of 140 sets of test results are analyzed, including 80 current only tests and 60 wave only tests. Siliceous sands with $d_{50}=0.37 \mathrm{~mm}$ and specific gravity of 2.70 were used in the experiments. The flow incident angle to the pipeline $\alpha$ ranges from $0^{\circ}$ to $45^{\circ}\left(0^{\circ}\right.$ denotes that the currents/ waves are perpendicular to the pipeline). The initial pipeline embedment depth $e$ is changed from $0.1 D$ to $0.5 D$. For current only tests, the depthaveraged flow velocity is varied from $0.28 \mathrm{~m} / \mathrm{s}$ to $0.42 \mathrm{~m} / \mathrm{s}$, with the corresponding Shields parameter $\theta\left(=U_{f}^{2} / g(s-1) d_{50}, U_{f}\right.$ is the bed shear velocity, $s$ is the specific gravity of sediment grains and $d_{50}$ is the representative diameter of sediment grains) ranging from 0.046 to 0.104 . For wave only tests, the $K C$ number ( $=U_{\mathrm{w}} T / D, U_{\mathrm{w}}$ is the wave orbital velocity, $T$ is the wave period, and $D$ is the diameter of the pipeline) is varied from 8.7 to 18.0 , with the corresponding $\theta_{\mathrm{w}}=0.096 \sim 0.192$.

\section{TEST RESULTS AND DISCUSSIONS}

\subsection{Test conditions and typical results}

Figure 3(a) (d) present the experimental results of different 3D scour propagation modes, demonstrated by the time-variant scour depths measured by the scour probes (No.1-13) along the left half of the pipeline (see Fig. 1) under different flow conditions.. In Figure 3(a), for $\theta=0.064, e / D=0.2$, and $\alpha=0^{\circ}$, it is found that the scour depth of each scour probe keeps almost zero at the initial stage. However, beyond a certain time instance, the scour curve jumps suddenly from zero and increases rapidly. Thereafter, the scour depth grows gently and approaches an equilibrium state. It is also found that the scour occurs sequentially from probe No. 1 to probe No. 13 at different time, meaning that the scour propagation along the pipeline throughout the flume width from the initial worm hole to the flume wall. In this study, the propagation rate is calculated based on the distance and the corresponding time difference between two consecutive probes, as applied in Cheng et al $(2009,2014)$. Figure 3 (a) shows the most common mode of scour propagation in present study.

In Figure $3(b)$ with $\theta=0.106, e / D=0.1$, and $\alpha=0^{\circ}$, it is seen that the local scour was initiated almost simultaneously along the pipeline once the tests started, and scour develops so fast that the system failed to measure the scour propagation rates. The mechanism of scour initiation for these cases was due to the piping of sediments underneath the pipeline discussed in Sumer and Fredsøe (2002) and Zang et al. (2009). It also has been examined by Cheng et al. (2014) that the critical condition for onset of scour was reached for these cases. In

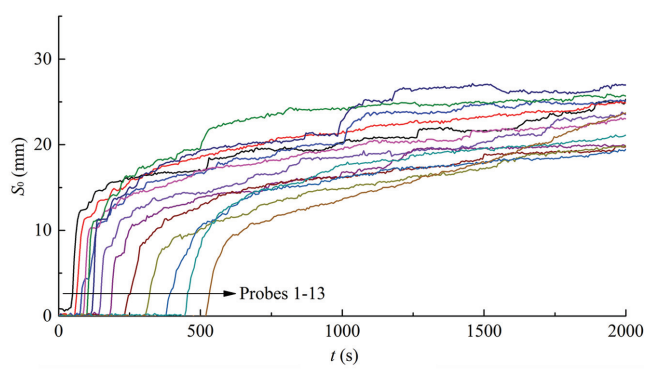

(a)

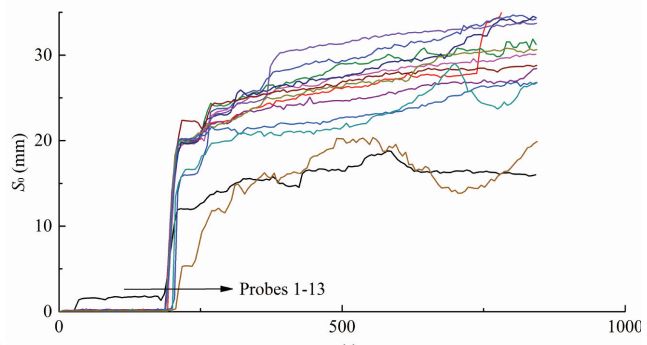

(b)

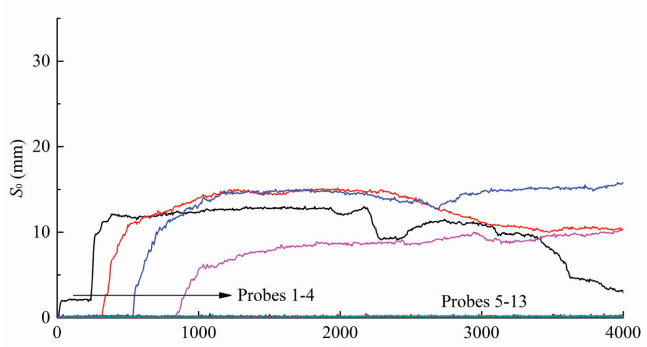

(c)

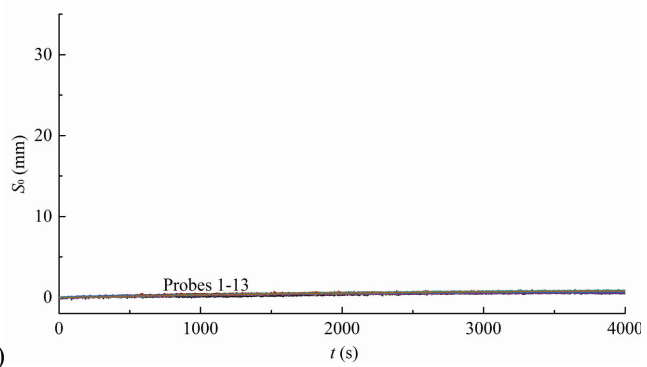

Figure 3. Typical results of 3D scour propagation along the pipeline, (a) $\theta=0.064, e / D=0.2, \alpha=0^{\circ}$, Scour propagation through the width of flume, (b) $\theta=0.0106$, $e / D=0.1, \alpha=0^{\circ}$, onset of scour at multiple locations by piping, (c) $\theta=0.064, e / D=0.3, \alpha=30^{\circ}$, scour propagation with a limited distance or backfill, (d) $\theta=0.046$, $e / D=0.4$, and $\alpha=30^{\circ}$, no scour propagation observed.

Figure 3 (c), $\theta=0.064, e / D=0.3$, and $\alpha=30^{\circ}$, it is found that the local scour only propagates among several scour probes from the initial worm hole (from probe No. 1 to probe No. 4), and then ceases, 
Table 1. Test conditions and results in currents.

\begin{tabular}{|c|c|c|c|c|c|}
\hline Test No. & $\alpha\left(^{\circ}\right)$ & $e / D$ & $U(\mathrm{~m} / \mathrm{s})$ & $\theta$ & Modes \\
\hline $\mathrm{c} 400 \mathrm{e} 1$ & 0 & 0.1 & 0.28 & 0.046 & SP \\
\hline $\mathrm{c} 400 \mathrm{e} 2$ & 0 & 0.2 & 0.28 & 0.046 & SP \\
\hline $\mathrm{c} 400 \mathrm{e} 3$ & 0 & 0.3 & 0.28 & 0.046 & SP \\
\hline $\mathrm{c} 400 \mathrm{e} 4$ & 0 & 0.4 & 0.28 & 0.046 & PB \\
\hline $\mathrm{c} 400 \mathrm{e} 5$ & 0 & 0.5 & 0.28 & 0.046 & NP \\
\hline $\mathrm{c} 450 \mathrm{e} 1$ & 0 & 0.1 & 0.33 & 0.064 & SP \\
\hline $\mathrm{c} 450 \mathrm{e} 2$ & 0 & 0.2 & 0.33 & 0.064 & SP \\
\hline $\mathrm{c} 450 \mathrm{e} 3$ & 0 & 0.3 & 0.33 & 0.064 & SP \\
\hline c450e4 & 0 & 0.4 & 0.33 & 0.064 & SP \\
\hline $\mathrm{c} 450 \mathrm{e} 5$ & 0 & 0.5 & 0.33 & 0.064 & PB \\
\hline c500e1 & 0 & 0.1 & 0.37 & 0.081 & OP \\
\hline $\mathrm{c} 500 \mathrm{e} 2$ & 0 & 0.2 & 0.37 & 0.081 & SP \\
\hline $\mathrm{c} 500 \mathrm{e} 3$ & 0 & 0.3 & 0.37 & 0.081 & SP \\
\hline c500e4 & 0 & 0.4 & 0.37 & 0.081 & SP \\
\hline c500e 5 & 0 & 0.5 & 0.37 & 0.081 & SP \\
\hline c550e1 & 15 & 0.1 & 0.42 & 0.104 & OP \\
\hline $\mathrm{c} 550 \mathrm{e} 2$ & 15 & 0.2 & 0.42 & 0.104 & SP \\
\hline $\mathrm{c} 550 \mathrm{e} 3$ & 15 & 0.3 & 0.42 & 0.104 & SP \\
\hline c550e4 & 15 & 0.4 & 0.42 & 0.104 & SP \\
\hline $\mathrm{c} 550 \mathrm{e} 5$ & 15 & 0.5 & 0.42 & 0.104 & SP \\
\hline a $15 \mathrm{c} 400 \mathrm{e} 1$ & 15 & 0.1 & 0.28 & 0.046 & SP \\
\hline a15c400e 2 & 15 & 0.2 & 0.28 & 0.046 & SP \\
\hline a $15 c 400 \mathrm{e} 3$ & 15 & 0.3 & 0.28 & 0.046 & PB \\
\hline a $15 \mathrm{c} 400 \mathrm{e} 4$ & 15 & 0.4 & 0.28 & 0.046 & $\mathrm{~PB}$ \\
\hline a $15 \mathrm{c} 400 \mathrm{e} 5$ & 15 & 0.5 & 0.28 & 0.046 & NP \\
\hline a15c450e1 & 15 & 0.1 & 0.33 & 0.064 & $\mathrm{SP}$ \\
\hline a $15 \mathrm{c} 450 \mathrm{e} 2$ & 15 & 0.2 & 0.33 & 0.064 & SP \\
\hline a $15 \mathrm{c} 450 \mathrm{e} 3$ & 15 & 0.3 & 0.33 & 0.064 & SP \\
\hline a15c450e4 & 15 & 0.4 & 0.33 & 0.064 & PB \\
\hline a $15 \mathrm{c} 450 \mathrm{e} 5$ & 15 & 0.5 & 0.33 & 0.064 & NP \\
\hline a15c500e1 & 15 & 0.1 & 0.37 & 0.081 & SP \\
\hline a $15 c 500 \mathrm{e} 2$ & 15 & 0.2 & 0.37 & 0.081 & SP \\
\hline a15c500e3 & 15 & 0.3 & 0.37 & 0.081 & SP \\
\hline a $15 c 500 e 4$ & 15 & 0.4 & 0.37 & 0.081 & SP \\
\hline a $15 \mathrm{c} 500 \mathrm{e} 5$ & 15 & 0.5 & 0.37 & 0.081 & PB \\
\hline a15c550e1 & 30 & 0.1 & 0.42 & 0.104 & $\mathrm{OP}$ \\
\hline a15c550e 2 & 30 & 0.2 & 0.42 & 0.104 & SP \\
\hline a $15 \mathrm{c} 550 \mathrm{e} 3$ & 30 & 0.3 & 0.42 & 0.104 & SP \\
\hline a $15 \mathrm{c} 550 \mathrm{e} 4$ & 30 & 0.4 & 0.42 & 0.104 & SP \\
\hline a $15 \mathrm{c} 550 \mathrm{e} 5$ & 30 & 0.5 & 0.42 & 0.104 & SP \\
\hline a30c400e1 & 30 & 0.1 & 0.28 & 0.046 & SP \\
\hline a30c400e 2 & 30 & 0.2 & 0.28 & 0.046 & PB \\
\hline a30c400e3 & 30 & 0.3 & 0.28 & 0.046 & PB \\
\hline a30c400e4 & 30 & 0.4 & 0.28 & 0.046 & $\mathrm{~PB}$ \\
\hline a30c400e 5 & 30 & 0.5 & 0.28 & 0.046 & NP \\
\hline $\mathrm{a} 30 \mathrm{c} 450 \mathrm{e} 1$ & 30 & 0.1 & 0.33 & 0.064 & SP \\
\hline a30c450e 2 & 30 & 0.2 & 0.33 & 0.064 & SP \\
\hline a30c450e3 & 30 & 0.3 & 0.33 & 0.064 & PB \\
\hline a30c450e4 & 30 & 0.4 & 0.33 & 0.064 & PB \\
\hline a30c450e 5 & 30 & 0.5 & 0.33 & 0.064 & NP \\
\hline a30c500e1 & 30 & 0.1 & 0.37 & 0.081 & SP \\
\hline a30c500e 2 & 30 & 0.2 & 0.37 & 0.081 & SP \\
\hline a30c500e3 & 30 & 0.3 & 0.37 & 0.081 & SP \\
\hline a30c500e4 & 30 & 0.4 & 0.37 & 0.081 & PB \\
\hline
\end{tabular}

(Continued)
Table 1. (Continued)

\begin{tabular}{llllll}
\hline Test No. & $\alpha\left(^{\circ}\right)$ & $e / D$ & $U(\mathrm{~m} / \mathrm{s})$ & $\theta$ & Modes \\
\hline a30c500e5 & 30 & 0.5 & 0.37 & 0.081 & PB \\
a30c550e1 & 45 & 0.1 & 0.42 & 0.104 & SP \\
a30c550e2 & 45 & 0.2 & 0.42 & 0.104 & SP \\
a30c550e3 & 45 & 0.3 & 0.42 & 0.104 & SP \\
a30c550e4 & 45 & 0.4 & 0.42 & 0.104 & SP \\
a30c550e5 & 45 & 0.5 & 0.42 & 0.104 & PB \\
a45c400e1 & 45 & 0.1 & 0.28 & 0.046 & PB \\
a45c400e2 & 45 & 0.2 & 0.28 & 0.046 & PB \\
a45c400e3 & 45 & 0.3 & 0.28 & 0.046 & PB \\
a45c400e4 & 45 & 0.4 & 0.28 & 0.046 & NP \\
a45c400e5 & 45 & 0.5 & 0.28 & 0.046 & NP \\
a45c450e1 & 45 & 0.1 & 0.33 & 0.064 & SP \\
a45c450e2 & 45 & 0.2 & 0.33 & 0.064 & PB \\
a45c450e3 & 45 & 0.3 & 0.33 & 0.064 & PB \\
a45c450e4 & 45 & 0.4 & 0.33 & 0.064 & NP \\
a45c450e5 & 45 & 0.5 & 0.33 & 0.064 & NP \\
a45c500e1 & 45 & 0.1 & 0.37 & 0.081 & SP \\
a45c500e2 & 45 & 0.2 & 0.37 & 0.081 & SP \\
a45c500e3 & 45 & 0.3 & 0.37 & 0.081 & PB \\
a45c500e4 & 45 & 0.4 & 0.37 & 0.081 & PB \\
a45c500e5 & 45 & 0.5 & 0.37 & 0.081 & NP \\
a45c550e1 & 45 & 0.1 & 0.42 & 0.104 & SP \\
a45c550e2 & 45 & 0.2 & 0.42 & 0.104 & SP \\
a45c550e3 & 45 & 0.3 & 0.42 & 0.104 & SP \\
a45c550e4 & 45 & 0.4 & 0.42 & 0.104 & SP \\
a45c550e5 & 45 & 0.5 & 0.42 & 0.104 & PB \\
\hline & & & & \\
\hline
\end{tabular}

*NA — Not Available; OP_-Onset by Piping; SP-Scour Propagates; PB —-Propagates and then Backfill; NP-No Propagation.

while for the other scour probes (No. $5 \sim 13$ ), the scour below the pipeline hasn't been detected. It is interesting to find that the scour hole was even backfilled with the elapse of time for probe No. 1. In Figure 3 (d) with $\theta=0.046, e / D=0.4$, and $\alpha=30^{\circ}$, the scour curve keeps almost zero during the test, demonstrating that there is no local scour below the pipeline at all probes, namely, the scour propagation doesn't occur.

Figure 3(a) (d) present four modes of 3D scour propagation observed in present study under different test conditions. Hence, it is speculated that the modes of 3D scour is much dependent on the Shields parameter (flow velocity), the embedment depth and the flow incident angle. In order to support the above claims, Table 1 lists the test conditions for current only tests, including the Shields parameter $\theta$, the flow incident angle $\alpha$ and the embedment depth ratio $e / D$ as well as the $3 \mathrm{D}$ scour propagation modes in the last column. Here, the modes of scour propagation are denoted by abbreviations. "SP" illustrates that the scour propagates over the total length of the model pipe. "OP" 
Table 2. Test conditions and results in waves.

\begin{tabular}{|c|c|c|c|c|c|c|}
\hline Test No. & $\alpha\left(^{\circ}\right)$ & $e / D$ & $H(\mathrm{~m})$ & $T(\mathrm{~s})$ & $K C$ & Modes \\
\hline $\mathrm{w} 15 \mathrm{t} 15 \mathrm{e} 1$ & 0 & 0.1 & 0.13 & 1.5 & 8.7 & SP \\
\hline $\mathrm{w} 15 \mathrm{t} 15 \mathrm{e} 2$ & 0 & 0.2 & 0.13 & 1.5 & 8.7 & SP \\
\hline $\mathrm{w} 15 \mathrm{t} 15 \mathrm{e} 3$ & 0 & 0.3 & 0.13 & 1.5 & 8.7 & PB \\
\hline $\mathrm{w} 15 \mathrm{t} 15 \mathrm{e} 4$ & 0 & 0.4 & 0.13 & 1.5 & 8.7 & PB \\
\hline $\mathrm{w} 15 \mathrm{t} 15 \mathrm{e} 5$ & 0 & 0.5 & 0.13 & 1.5 & 8.7 & NP \\
\hline w16t18e1 & 0 & 0.1 & 0.17 & 1.8 & 15.8 & SP \\
\hline $\mathrm{w} 16 \mathrm{t} 18 \mathrm{e} 2$ & 0 & 0.2 & 0.17 & 1.8 & 15.8 & SP \\
\hline w16t18e3 & 0 & 0.3 & 0.17 & 1.8 & 15.8 & SP \\
\hline w16t18e4 & 0 & 0.4 & 0.17 & 1.8 & 15.8 & PB \\
\hline w16t18e5 & 0 & 0.5 & 0.17 & 1.8 & 15.8 & NP \\
\hline w16t20e1 & 0 & 0.1 & 0.15 & 2.0 & 18.0 & $\mathrm{SP}$ \\
\hline $\mathrm{w} 16 \mathrm{t} 20 \mathrm{e} 2$ & 0 & 0.2 & 0.15 & 2.0 & 18.0 & SP \\
\hline $\mathrm{w} 16 \mathrm{t} 20 \mathrm{e} 3$ & 0 & 0.3 & 0.15 & 2.0 & 18.0 & SP \\
\hline $\mathrm{w} 16 \mathrm{t} 20 \mathrm{e} 4$ & 0 & 0.4 & 0.15 & 2.0 & 18.0 & $\mathrm{~PB}$ \\
\hline w16t20e5 & 0 & 0.5 & 0.15 & 2.0 & 18.0 & NP \\
\hline a15w15t15e1 & 15 & 0.1 & 0.13 & 1.5 & 8.7 & SP \\
\hline a $15 \mathrm{w} 15 \mathrm{t} 15 \mathrm{e} 2$ & 15 & 0.2 & 0.13 & 1.5 & 8.7 & SP \\
\hline a $15 \mathrm{w} 15 \mathrm{t} 15 \mathrm{e} 3$ & 15 & 0.3 & 0.13 & 1.5 & 8.7 & SP \\
\hline a $15 w 15 t 15 e 4$ & 15 & 0.4 & 0.13 & 1.5 & 8.7 & PB \\
\hline a15w $15 \mathrm{t} 15 \mathrm{e} 5$ & 15 & 0.5 & 0.13 & 1.5 & 8.7 & NP \\
\hline a15w16t18e1 & 15 & 0.1 & 0.17 & 1.8 & 15.8 & OP \\
\hline a15w16t18e2 & 15 & 0.2 & 0.17 & 1.8 & 15.8 & SP \\
\hline a15w16t18e3 & 15 & 0.3 & 0.17 & 1.8 & 15.8 & SP \\
\hline a15w16t18e4 & 15 & 0.4 & 0.17 & 1.8 & 15.8 & PB \\
\hline a15w16t18e5 & 15 & 0.5 & 0.17 & 1.8 & 15.8 & NP \\
\hline a15w16t20e1 & 15 & 0.1 & 0.15 & 2.0 & 18.0 & SP \\
\hline a $15 w 16 t 20 e 2$ & 15 & 0.2 & 0.15 & 2.0 & 18.0 & SP \\
\hline a $15 w 16 t 20 e 3$ & 15 & 0.3 & 0.15 & 2.0 & 18.0 & SP \\
\hline a15w16t20e4 & 15 & 0.4 & 0.15 & 2.0 & 18.0 & SP \\
\hline a $15 w 16 t 20 e 5$ & 15 & 0.5 & 0.15 & 2.0 & 18.0 & NP \\
\hline a30w15t15e1 & 30 & 0.1 & 0.13 & 1.5 & 8.7 & SP \\
\hline a30w $15 \mathrm{t} 15 \mathrm{e} 2$ & 30 & 0.2 & 0.13 & 1.5 & 8.7 & SP \\
\hline a30w15t15e3 & 30 & 0.3 & 0.13 & 1.5 & 8.7 & PB \\
\hline a30w15t15e4 & 30 & 0.4 & 0.13 & 1.5 & 8.7 & PB \\
\hline a30w15t15e 5 & 30 & 0.5 & 0.13 & 1.5 & 8.7 & NP \\
\hline a30w16t18e1 & 30 & 0.1 & 0.17 & 1.8 & 15.8 & SP \\
\hline a30w16t18e2 & 30 & 0.2 & 0.17 & 1.8 & 15.8 & SP \\
\hline a30w16t18e3 & 30 & 0.3 & 0.17 & 1.8 & 15.8 & SP \\
\hline a30w16t18e4 & 30 & 0.4 & 0.17 & 1.8 & 15.8 & PB \\
\hline a30w16t18e5 & 30 & 0.5 & 0.17 & 1.8 & 15.8 & NP \\
\hline a30w16t20e1 & 30 & 0.1 & 0.15 & 2.0 & 18.0 & $\mathrm{SP}$ \\
\hline a30w16t20e2 & 30 & 0.2 & 0.15 & 2.0 & 18.0 & SP \\
\hline a30w16t20e3 & 30 & 0.3 & 0.15 & 2.0 & 18.0 & PB \\
\hline a30w16t20e4 & 30 & 0.4 & 0.15 & 2.0 & 18.0 & PB \\
\hline a30w16t20e5 & 30 & 0.5 & 0.15 & 2.0 & 18.0 & NP \\
\hline $\mathrm{a} 45 \mathrm{w} 15 \mathrm{t} 15 \mathrm{e} 1$ & 45 & 0.1 & 0.13 & 1.5 & 8.7 & $\mathrm{SP}$ \\
\hline $\mathrm{a} 45 \mathrm{w} 15 \mathrm{t} 15 \mathrm{e} 2$ & 45 & 0.2 & 0.13 & 1.5 & 8.7 & SP \\
\hline $\mathrm{a} 45 \mathrm{w} 15 \mathrm{t} 15 \mathrm{e} 3$ & 45 & 0.3 & 0.13 & 1.5 & 8.7 & PB \\
\hline $\mathrm{a} 45 \mathrm{w} 15 \mathrm{t} 15 \mathrm{e} 4$ & 45 & 0.4 & 0.13 & 1.5 & 8.7 & NP \\
\hline $\mathrm{a} 45 \mathrm{w} 15 \mathrm{t} 15 \mathrm{e} 5$ & 45 & 0.5 & 0.13 & 1.5 & 8.7 & NP \\
\hline $\mathrm{a} 45 \mathrm{w} 16 \mathrm{t} 18 \mathrm{e} 1$ & 45 & 0.1 & 0.17 & 1.8 & 15.8 & $\mathrm{SP}$ \\
\hline $\mathrm{a} 45 \mathrm{w} 16 \mathrm{t} 18 \mathrm{e} 2$ & 45 & 0.2 & 0.17 & 1.8 & 15.8 & SP \\
\hline $\mathrm{a} 45 \mathrm{w} 16 \mathrm{t} 18 \mathrm{e} 3$ & 45 & 0.3 & 0.17 & 1.8 & 15.8 & SP \\
\hline $\mathrm{a} 45 \mathrm{w} 16 \mathrm{t} 18 \mathrm{e} 4$ & 45 & 0.4 & 0.17 & 1.8 & 15.8 & NP \\
\hline
\end{tabular}

(Continued)
Table 2. (Continued)

\begin{tabular}{lllllll}
\hline Test No. & $\alpha\left(^{\circ}\right)$ & $e / D$ & $H(\mathrm{~m})$ & $T(\mathrm{~s})$ & $K C$ & Modes \\
\hline a45w16t18e5 & 45 & 0.5 & 0.17 & 1.8 & 15.8 & $\mathrm{NP}$ \\
a45w16t20e1 & 45 & 0.1 & 0.15 & 2.0 & 18.0 & SP \\
a45w16t20e2 & 45 & 0.2 & 0.15 & 2.0 & 18.0 & SP \\
a45w16t20e3 & 45 & 0.3 & 0.15 & 2.0 & 18.0 & PB \\
a45w16t20e4 & 45 & 0.4 & 0.15 & 2.0 & 18.0 & PB \\
a45w16t20e5 & 45 & 0.5 & 0.15 & 2.0 & 18.0 & NP \\
\hline
\end{tabular}

*NA-Not Available; OP — Onset by Piping; SP — Scour Propagates; $\mathrm{PB}$ - Propagates and then Backfill; NP-No Propagation.

represents that local scour was initiated almost simultaneously along the pipeline once the tests started. "PB" denotes that the scour only propagates for a certain distance, and then ceased by backfill with sediment. "NP" demonstrates that no scour propagation was observed. "NA" denotes that the test data is not available due to uncertain factors. The corresponding test conditions and results for wave only tests are listed in Table 2.

In the following section, the experimental results are analyzed based on different combinations of the concerned parameters in present study and the critical conditions for modes of scour propagation are examined.

\subsection{Modes of $3 D$ scour propagation}

As depicted in Section 3.1, the 3D scour propagation along the pipeline shows different modes after the local scour was initiated at the middle of the pipeline. Through analyzing the test data, it is found that eachscour propagation modes corresponds to certain flow conditions. For example, mode "NP" often takes place for the cases with large initial embedment depths, low Shields parameter (or $\mathrm{KC}$ number) and large flow incident angle. Mode "OP" occurs when the embedment depth is small and the Shields parameter or the KC number is large. Mode "PB" mostly occurs when the currents/waves attack the pipeline at large flow incident angles. Mode "SP" is the most common case, which is found for the moderate values of the Shields parameter and the embedment depth.

Figs. 4 (a) (d) show distributions of the 3D scour propagation modes in the map of $\theta$ vs. $e / D$ for $\alpha=0^{\circ}, 15^{\circ}, 30^{\circ}$ and $45^{\circ}$, respectively. Generally, with the increase of the embedment and decrease of the Shields parameter, the 3D scour propagation may show "OP", "SP", "PB" and "NP" modes sequentially. Thus, the 3D scour propagation mode is determined by a combination of the initial embedment depth, the Shields parameter and the flow incident angle. 


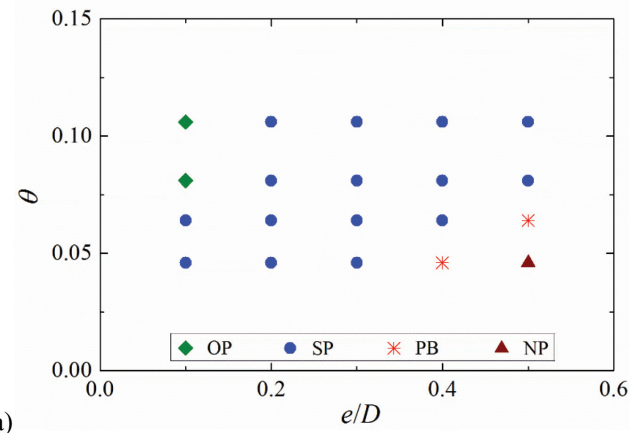

(a)

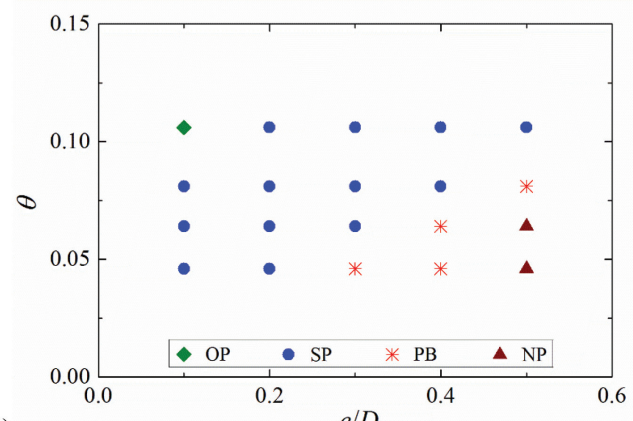

(b)

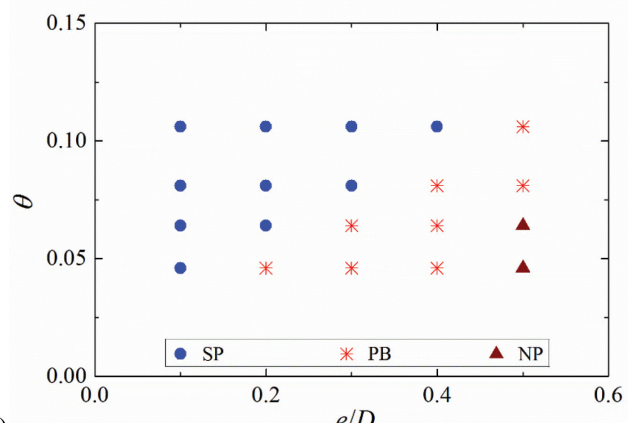

(c)

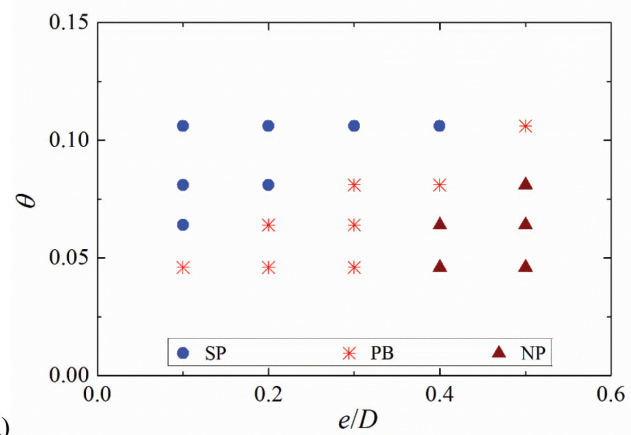

(d)

Figure 4. Distributions of 3D scour propagation modes in steady currents, (a) $\alpha=0^{\circ}$, (b) $\alpha=15^{\circ}$, (c) $\alpha=30^{\circ}$, (d) $\alpha=45^{\circ}$.

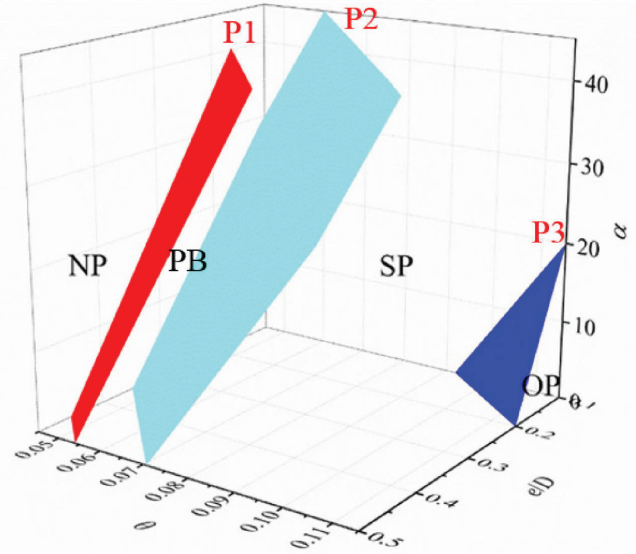

Figure 5. Critical conditions of 3D scour propagation modes in currents.

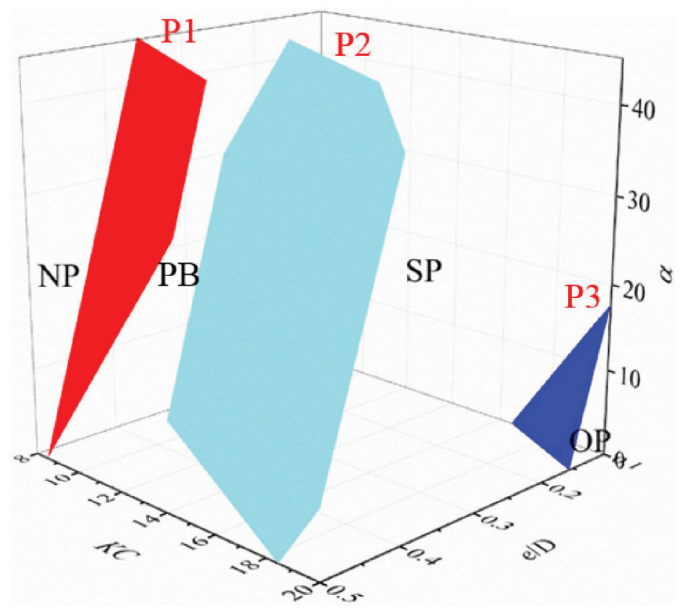

Figure 6. Critical conditions of 3D scour propagation modes in waves.

Here, the critical conditions for each mode of $3 \mathrm{D}$ scour propagation are obtained from the experimental results. For simplicity, a linear relationship for the three main parameters is applied to differentiate the $3 \mathrm{D}$ scour modes:

$a \frac{e}{D}+b \theta+c \alpha+d=0$

where, $a, b, c$ and $d$ are four constants and can be calibrated from the experimental results.

Eq. (1) represents a plane in the 3D space composed of theembedmentdepth, theShieldsparameter 
and the flow incident angle. Figure 5 shows the distributions of different modes of 3D scour propagation in steady currents. The space is divided into 4 parts by the three planes P1, P2 and $\mathrm{P} 3$. Since the three planes are assumed to be parallel to one another, the first three coefficients in Eq. (1) are kept constant and have the values of $a=0.162, b=-1.0, c=0.001$. Only the last coefficient has different values of $d=-0.03,-0.01$ and 0.08 for $\mathrm{P} 1, \mathrm{P} 2$ and $\mathrm{P} 3$, respectively.

Similarly, the distributions of different modes of $3 \mathrm{D}$ scour propagation in waves are shown in Figure 6 . The space is also divided into four parts by the three planes defined by Eq. (1). Different from the cases in steady currents, the Shields parameter in Eq. (1) is replaced by the $\mathrm{KC}$ number in waves. Here, the first three coefficients in Eq. (1) are $a=65.15, b=-1, c=0.2$ and the coefficient $d$ is $-24.07,-14.12$ and 8.93 for $\mathrm{P} 1, \mathrm{P} 2$ and P3, respectively. For practical applications, Eq. (1) may provide an estimation of the status of the $3 \mathrm{D}$ scour propagation along a pipeline if an initial hole is formed below the pipeline.

\section{CONCLUSIONS}

In this paper, the time-dependent scour depths along the pipeline measured by scour probes are analysed in steady current and waves. Four modes of $3 \mathrm{D}$ scour propagation along the pipeline were identified after the local scour was initiated below the pipeline. These modes include scour propagation throughout the whole pipeline, onset of scour at multiple locations by piping, scour propagation ceased by backfill and no propagation. The correlation of the critical conditions for the occurrence of these modes with the flow incident angle, the embedment depth and the Shields parameter are determined based on the experimental results.

\section{ACKNOWLEDGEMENTS}

The authors would like to acknowledge the support from National Natural Science Foundation of
China (51579232, 51479025, 51409035), and Open Funding of State Key Laboratory of Coastal and Offshore Engineering (LP1410).

\section{REFERENCES}

Brørs, B. 1999. Numerical modelling of flow and scour at pipelines. Journal of Hydraulic Engineering 125 (5): 511-523.

Cheng, L., Yeow, K., Zang, Z. \& Li F. 2014. 3D scour below pipelines under waves and combined waves and currents. Coastal Engineering 83: 137-149.

Cheng, L., Yeow, K., Zang, Z. \& Teng, B. 2009. Threedimensional scour below pipelines in steady currents. Coastal Engineering 56 (5-6): 577-590.

Chiew, Y. 1990. Mechanics of local around submarine pipeline. Journal of Hydraulic Engineering 116 (4): 515-529.

Fredsøe, J., Sumer, B.M. \& Arnskov, M. 1992. Time scale for wave/current scour below pipelines. International Journal for Offshore and Polar Engineering 2 (2): 13-17.

Fuhrman, D.F., Baykal, C., Sumer, B.M., Jacbsen, N.G. \& Fredsøe, J. 2014. Numerical simulation of waveinduced scour and backfilling processes beneath submarine pipelines. Coastal Engineering 94: 10-22.

Li, F. \& Cheng, L. 1999. A numerical model for local scour under offshore pipelines. Journal of Hydraulic Engineering 125 (4): 400-406.

Liang, D., Cheng, L. \& Li, F. 2005. Numerical modelling of scour below a pipeline in currents. Part II: scour simulation. Coastal Engineering 52 (1): 43-62.

Mao Y., 1988. Seabed scour under pipeline. Proc. 7th Conf. on Offshore Mechanics and Arctic Engineering, Pipeline Technology, Vol. V, ASME, Houston, Texas, pp. 33-38.

Sumer, B.M., Truelsen, C., Sichmann, T. \& Fredsøe, J. 2001. Onset of scour below pipelines and self-burial. Coastal Engineering 42 (4): 213-235.

Wu, Y. \& Chiew, Y.M. 2012. Three-dimensional scour at submarine pipelines. Journal of Hydraulic Engineering 138 (9): 788-795.

Zhou, T., Wang, H., Razali, S.F.M., Zhou, Y. \& Cheng, L. 2010. Three-dimensional vorticity measurements in the wake of a yawed circular cylinder. Physics of Fluids 22, 015108. 